\title{
BMJ Open Do consultants do what they say they do? Observational study of the extent to which clinicians involve their patients in the decision-making process
}

\author{
Ellen M Driever (1D , ${ }^{1}$ Anne M Stiggelbout (D) ,2 Paul L P Brand (D) ${ }^{3,4}$
}

To cite: Driever EM, Stiggelbout AM, Brand PLP. Do consultants do what they say they do? Observational study of the extent to which clinicians involve their patients in the decisionmaking process. BMJ Open 2022;12:e056471. doi:10.1136/ bmjopen-2021-056471

- Prepublication history and additional supplemental material for this paper are available online. To view these files, please visit the journal online (http://dx.doi.org/10.1136/ bmjopen-2021-056471)

Received 16 August 2021 Accepted 06 December 2021

\section{Check for updates}

(C) Author(s) (or their employer(s)) 2022. Re-use permitted under CC BY-NC. No commercial re-use. See rights and permissions. Published by BMJ.

${ }^{1}$ Innovation and Research, Isala Hospitals, Zwolle, The Netherlands

${ }^{2}$ Medical Decision Making Leiden University Medical Center, Leiden, The Netherlands ${ }^{3}$ Princess Amalia Children's Centre, Isala Klinieken, Zwolle, The Netherlands ${ }^{4}$ UMCG Postgraduate School of Medicine, University Medical Centre, Groningen, The Netherlands

Correspondence to Dr Ellen M Driever; e.m.driever@isala.nl

\section{ABSTRACT}

Objectives To assess whether consultants do what they say they do in reaching decisions with their patients. Design Cross-sectional analysis of hospital outpatient encounters, comparing consultants' self-reported usual decision-making style to their actual observed decisionmaking behaviour in video-recorded encounters.

Setting Large secondary care teaching hospital in the Netherlands.

Participants 41 consultants from 18 disciplines and 781 patients.

Primary and secondary outcome measure With the Control Preference Scale, the self-reported usual decisionmaking style was assessed (paternalistic, informative or shared decision making). Two independent raters assessed decision-making behaviour for each decision using the Observing Patient Involvement (OPTION) ${ }^{5}$ instrument ranging from 0 (no shared decision making (SDM)) to 100 (optimal SDM).

Results Consultants reported their usual decisionmaking style as informative $(n=11)$, shared $(n=16)$ and paternalistic $(n=14)$. Overall, patient involvement was low, with mean (SD) OPTION ${ }^{5}$ scores of 16.8 (17.1). In an unadjusted multilevel analysis, the reported usual decision-making style was not related to the OPTION ${ }^{5}$ score ( $p>0.156)$. After adjusting for patient, consultant and consultation characteristics, higher OPTION ${ }^{5}$ scores were only significantly related to the category of decisions (treatment vs the other categories) and to longer consultation duration $(p<0.001)$.

Conclusions The limited patient involvement that we observed was not associated with the consultants' selfreported usual decision-making style. Consultants appear to be unconsciously incompetent in shared decision making. This can hinder the transfer of this crucial communication skill to students and junior doctors.

\section{INTRODUCTION}

In Western societies, shared decision making (SDM) is increasingly championed by patients, clinician organisations and policy-makers as the preferred model for making patientcentred healthcare decisions ${ }^{1-5}$ and achieving value based healthcare. ${ }^{6}$ The implementation of SDM in clinical practice, however, remains suboptimal. $^{7-9}$ Clinician-reported barriers

\section{Strengths and limitations of this study}

- The main strength of our study was that we combined direct observations of consultants' shared decision making (SDM) behaviour with their selfreported usual decision-making style in a large sample of clinical decisions across 18 different disciplines.

- The results of this study can be used to optimise healthcare professionals' SDM training and support further implementation of this crucial skill.

- The consultants were aware of being recorded, which may have affected their SDM behaviour.

- The cross-sectional design of this study precludes causal inference of the associations we observed.

- The study was performed in a single, large hospital in the Netherlands, which may have limited the generalisability of our results to other settings and countries.

to applying SDM include time constraints and the perceived incapability of patients to participate in decision making. ${ }^{10}$ Advancing the implementation of SDM is also hindered by clinicians' perception that they already practise SDM. ${ }^{10} 11$ Several qualitative and quantitative studies in which clinicians were asked to report their usual decision-making style showed that clinicians feel that they already involve patients in decision making about their care. ${ }^{10-12}$ This finding contradicts the results of a systematic review of 33 studies, which showed that the degree of patient involvement in actual medical decision making is low. ${ }^{7}$ This raises the question of how accurate clinicians' judgments of their own decision-making behaviour are. This is important for several reasons. First, clinicians are role models for medical students and residents. They need to be aware of their role in the decision-making process and be competent in SDM to be able to demonstrate and teach this crucial communication skill to students and residents. Second, unreliable 
clinician self-reports of decision-making behaviours may undermine the accuracy and reliability of SDM research that is based on self-reported data. Third, the design of SDM training programmes partly depends on participants' awareness of their SDM competency. Skills training may be particularly effective if participants are aware of their incompetence, become motivated to change their behaviour and are willing to repeatedly reflect on their behaviour when applying the newly acquired skill to become better at it. ${ }^{13}$ To help advance the implementation of SDM and create awareness around personal biases, we sought to uncover/investigate a potential gap between clinicians' perceived and actual decision-making behaviour. Therefore, we studied whether consultants do what they say they do in reaching decisions with their patients. We compared their self-reported usual decisionmaking style with their actual decision-making behaviour in hospital-based consultations.

\section{METHODS}

We analysed videorecorded outpatient encounters between medical consultants and their patients in Isala Hospital, a large general teaching hospital serving a population of approximately 600000 people in a mixed urban-rural area in the Netherlands. We used a single camera with a fixed focus on the consultant only. The consultations were recorded between November 2018 and April 2019.

\section{Participants and recruitment procedure}

All participating medical consultants were recruited among participants of our previous cross-sectional survey. ${ }^{11}$ The consultants were invited via email by the main researcher (EMD) to participate in this observational study of video-taped encounters. There was no working relationship or power relation between the researchers and the consultants who were invited and we made it clear in the information for participants that participation was voluntary. Participants were not recruited based on specific characteristics.

We aimed to include a minimum of 30 consultants and 10 encounters per consultant, which is a requirement for multilevel analysis of nested observations at the level of the healthcare professional. ${ }^{14}$ We enrolled consecutive outpatients of the participating consultants. To protect the patients' anonymity, we only captured them on audio. All participants, consultants and patients, provided written informed consent.

\section{Coding}

Usual style of decision making

In our previous study, we obtained the participating consultants' perceptions of their usual style of medical decision making with the modified Control Preference Scale (CPS). Their responses to the CPS questions, were classified as paternalistic (clinician decides), informative (patient decides) or SDM. ${ }^{11}$

\section{Decision types}

Two researchers (EMD and R Hartog) distinguished the main decision from all other decisions in a consultation (decision type). The main decision was defined as the decision that was directly related to the patient's chief complaint as expressed during the consultation. Differences in decision type classification between researchers were resolved by discussion with an independend third researcher (PLPB) and consensus. Then we categorised the main decisions into three decision types: diagnostic (gathering additional information), treatment and follow-up. We chose the consultants' main decisions for our analyses because we assumed that they had the major decisions in mind when they reported their usual decision-making behaviour.

\section{Observed patient involvement}

Several instruments are available to asses SDM in medical consultations. The Observing Patient Involvement (OPTION) scale, developed by Elwyn et al assesses the extent to which consultants involve patients in the decisionmaking process (for the items see online supplemental table A) ${ }^{15}$ This instrument has been used frequently in SDM research. Because it focuses on clinician behaviour, it appeared suitable for our research question. The OPTION $^{5}$ is the validated concise version of the OPTION instrument ${ }^{15}$ and is considered to be more efficient with lower cognitive burden for raters than the original 12-item instrument ${ }^{16}$ Following the OPTION ${ }^{5}$ manual, each item was scored on a Likert-scale ranging from 0 (no effort) to 4 (exemplary effort). Following recommendation of the OPTION ${ }^{5}$ scoring manual, these items were rescaled by a factor 5 (resulting in items scores ranging from 0 to 20 , and total scores ranging from 0 to $100 .^{17}$ Two trained researchers (EMD, a medical doctor and $\mathrm{RH}$, a linguistics master student) independently scored the first 29 videotaped encounters using the OPTION ${ }^{5}$. Then they compared and discussed scoring differences until consensus was reached. In the next step, they independently scored 179 subsequent encounters to assess inter-observer reliability. After we found good inter-rater agreement (intraclass correlation coefficient $=0.938$ ), the remaining consultations were scored by one researcher.

\section{Statistical analysis}

The OPTION ${ }^{5}$ instrument is ordinal by design, which implies that nonparametric statistical analyses are required. In most studies, however, OPTION ${ }^{5}$ scores have been analysed as a continuous variable using parametric statistical techniques. ${ }^{14}$ Therefore, we assessed the differences in OPTION $^{5}$ scores between groups using both nonparametric and parametric analyses. Since these analyses showed comparable results and to facilitate comparison with other studies, further data analysis was carried out using parametric tests only. Given the nested nature of the data, with multiple observations for each participating consultant, we selected multilevel modelling as the most appropriate method for analysis. We built random 


\section{Usual decision-making style}

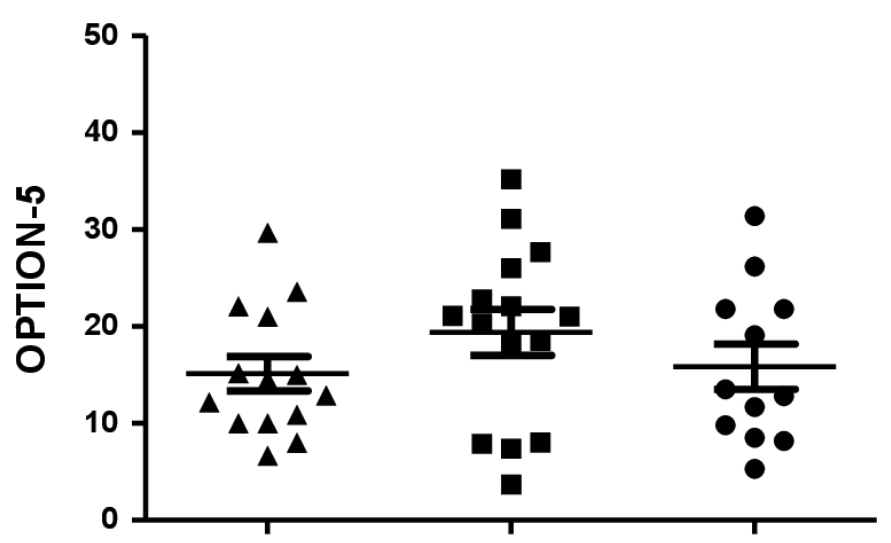

\section{Paternalistic SDM Informative}

Figure 1 Mean patient involvement $(\mathrm{OPTION})^{5}$ (on a scale 0-100) of 41 medical consultants (with 727 patients) by self-reported usual decision-making style assessed with modified Control Preference Scale: paternalistic, shared and informative decision making. OPTION, Observing Patient Involvement; SDM, shared decision making.

intercept models, with the self-reported usual decisionmaking style as the predictor and the OPTION ${ }^{5}$ scores of the main decisions as outcomes. We adjusted for potential confounding variables such as decision type, consultants' and patients' age and gender, consultation duration, consultation type (new patient, or follow-up consultation) and discipline (medical, or surgical, as described earlier. ${ }^{18}$ For all analyses, the alpha level was set at 0.05 . Univariate analyses were performed using SPSS (V.26). Multilevel analyses were performed using MLWIN (V.3.04).

\section{Patient and public involvement}

Neither study participants nor the public were involved in the study design or data analysis.

\section{RESULTS}

Forty-one consultants (28 males, 68\%) participated in our study with a mean age (SD) of 47.9 (8.0) years, from 18 specialties (23 from medical and 18 from surgical discipline, see online supplemental table B). Fourteen participants had reported paternalistic decision making, 16 SDM and 11 informative decision making as their usual decision-making style in our previous study. ${ }^{11}$ In total, 781 patients (15-24 per consultant) participated in our study. After excluding 36 consultations from the analysis because of insufficient audio quality and 18 preoperative anaesthesiology consultations in which no decisions were made, we analysed 1564 decisions from 727 consultations. The median (range) number of decisions per consultation was two (1-6). Of the 727 patients, 347 were male $(48 \%)$, and the mean (SD) age was 48.6 (24.6) years. There were 239 consultations with new patients (33\%) and 488 follow-up consultations (67\%). The mean (SD) duration of the consultations was 15 (9) minutes, with a minimum of 1 and maximum of $50 \mathrm{~min}$.

\section{OPTION ${ }^{5}$ scores}

Scores on the 5 items of the OPTION ${ }^{5}$ (see online supplemental table A) were expressed on a scale ranging from 0 (no SDM) to 20 (optimal SDM) per item. The highest scores were found for item 1 (the consultant draws attention to, or confirms, that alternate management options exist, recognising the need for a decision; mean (SD) score 5.1 (4.0) (on a 0 to 20 scale) and item 3 (the consultant gives information, or checks understanding, about the reasonable options that are available for the patient, including the choice of 'no action'; mean (SD) score 4.7 (5.0) on a 0 to 20 scale. Intermediate scores were found for item 4 (the consultant elicits the patient's preferred option(s); mean (SD) scores 3.3 (4.4)) and item 5 (the consultant makes an effort to integrate the patient's elicited preferences in the decision-making process; mean (SD) score 2.9 (4.1), each om a 0-20 scale. The lowest scores were found for item 2 (the consultant supports the patient to become informed or deliberate about the options; mean (SD) score of 0.9 (2.4) on a 0 to 20 scale.

The mean (SD) total OPTION ${ }^{5}$ score for the main decision was 16.8 (17.1) on a scale ranging from 0 (no SDM) to 100 (optimal SDM). The OPTION ${ }^{5}$ scores varied both within and between consultants, see figures 1 and 2). Univariate analysis showed that the mean (SD) OPTION ${ }^{5}$ scores on consultations of consultants who reported SDM (18.9 (17.3) on a $0-100$ scale). as their usual decisionmaking style were slightly higher than the mean scores on consultations of consultants who reported an informative
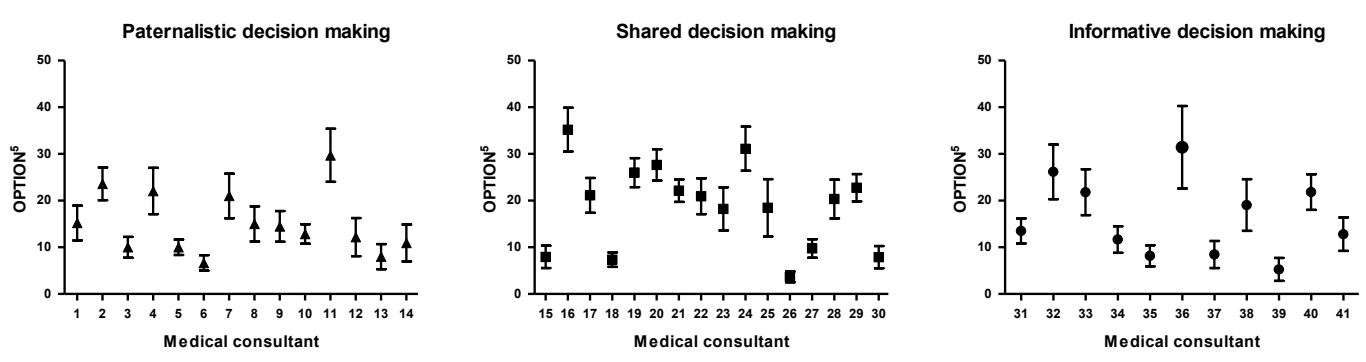

Figure 2 Mean and SE of the mean of patient involvement (OPTION) ${ }^{5}$ scores (scale 0-100) in consultation of 41 medical consultants (with 727 patients) by self-reported usual decision-making role: paternalistic, shared or informative decision making. OPTION, Observing Patient Involvement. 
Table 1 Random-intercept regression models for the presence of patient involvement (OPTION) $)^{5}$ in 727 main decisions in encounters of 41 consultants with 727 patients

\begin{tabular}{|c|c|c|c|}
\hline Variable & & $\begin{array}{l}\text { Final model * } \\
\text { coefficient (SE) }\end{array}$ & $P$ value \\
\hline Intercept † & & $19.17(0.80)$ & $<0.001$ \\
\hline \multicolumn{4}{|l|}{ Consultant-level predictors } \\
\hline \multirow[t]{2}{*}{ Self-reported usual role $\ddagger$} & SDM & Reference & \\
\hline & Paternalistic & $-1.60(2.84)$ & 0.573 \\
\hline \multirow[t]{3}{*}{ Decision category } & Treatment & Reference & \\
\hline & Diagnostic & $-5.59(1.50)$ & $<0.001$ \\
\hline & Follow-up & $-10.34(1.75)$ & $<0.001$ \\
\hline Consultation duration & Minutes & $0.73(0.07)$ & $<0.001$ \\
\hline
\end{tabular}

${ }^{*}$ This final model fitted the data best. The model including all patient and consultant characteristics is presented in online supplemental table C. This full model showed similar results to the model presented in table 1, but with lower overall fit.

†Intercept=The intercept can be interpreted as the average patient involvement of a (hypothetical) subject scoring 0 for each predictor in the model.

¥Self-reported usual decision-making role in previous study. ${ }^{11}$

OPTION, Observing Patient Involvement; SDM, shared decision making.

(15.6 (17.9)) or paternalistic style of decision making (15.0 (15.8), $\mathrm{p}=0.017)$. In an unadjusted multilevel analysis, the reported usual decision-making style was not related to the OPTION ${ }^{5}$ score $(\mathrm{p}>0.156)$. After adjusting for patient, consultant and consultation characteristics, higher OPTION ${ }^{5}$ scores were only significantly related to the category of decisions (treatment vs the other categories) and longer consultation duration. Table 1 presents the model that best fitted the data. The full model including all patient and consultant characteristics is presented in online supplemental table C. This full model showed similar results but provided a poorer overall fit to the data compared with the model presented in table 1.

\section{DISCUSSION}

Using self-reported statements of usual decision-making style and an independent assessment of consultants' actual decision-making behaviour in video-recorded consultations we sought to investigate a potential gap between consultants' perceived and actual decision-making behaviours in consultations. In a multilevel analysis of our data, the observed degree of patient involvement in video-recorded consultations was not associated with the consultants' self-reported usual decision-making style. In other words, the medical consultants in this study did not do what they said they did in reaching decisions with their patients. Following four stages of competence model that is commonly used in the training of clinical skills ${ }^{19}$ these consultants can be described as 'unconsciously incompetent' in SDM. This is important because they are the role models for medical students and junior doctors. To be able to demonstrate and teach this crucial communication skill to medical learnes, consultants need to be aware of their role in the decision-making process and be competent in SDM. To be receptive to SDM training, consultants first need to be consciously aware of their limited skills in involving patients in treatment decisions ('conscious incompetence' in Broadwell's and Maslow's model). In our study, only the consultants who had reported paternalistic decision making as their usual style appeared to be 'consciously incompetent' in the terminology of this model. In addition, the discrepancy between consultants' self-reported usual decision-making style and the observed patient involvement in their consultations undermines the validity of SDM research using self-reported measures.

\section{Comparison with other studies}

Patient involvement was limited, with mean OPTION $^{5}$ scores below the proposed cut-off value of $25,{ }^{7}$ which is comparable to several other studies. ${ }^{9}{ }^{20}$ We found considerable differences in OPTION $^{5}$ scores between consultations of each individual consultant (figure 2), suggesting that individual consultants' patient involvement behaviour is variable. Further research is needed to explore the reasons for this variation, which could be related to physician, patient or organisational factors. Limited patient involvement was associated with decision type (treatment vs diagnostic or follow-up decisions) and longer consultation duration (table 1). The crosssectional nature of our study did not allow us to identify what the cause is and what the effect. (Lack of) time is often reported as a key barrier to the application of SDM in clinical practice. ${ }^{10} 21-23$ The literature on the actual impact of applying SDM on consultation duration is too scant to allow a clear estimation of the effects. ${ }^{23} 24$ Patient and consultant characteristics such as age and gender 
were not related to the OPTION ${ }^{5}$ scores in the multilevel model (table 1 and online supplemental table $\mathrm{C}$ ). This is in accordance with a systematic review of 33 studies on OPTION $^{5}$ scores. ${ }^{7}$

The previous literature comparing clinicians' selfreported and actual decision-making style in medical consultations also showed that clinicians tend to overestimate the extent to which they apply SDM. ${ }^{2025}$ These studies analysed simple decisions in primary care such as refills and routine testing ${ }^{20}$ or were performed in specific breast cancer or renal failure clinics in which the staff had been extensively trained in the application of SDM. ${ }^{25}$

\section{Strengths and limitations}

The main strength of our study was that we combined direct observations of consultants' SDM behaviour in a large sample of clinical decisions across 18 different disciplines with their self-reported usual decision-making style. We acknowledge the following limitations of our study. First, the consultants were aware that their behaviour in the decision-making process was recorded and assessed, which may have prompted them to show more SDM behaviour than they otherwise would. However, so far, there is no indication that videotaping consultations has an effect on clinicians' behaviour. ${ }^{26} 27$ Second, the crosssectional design of this study precludes causal inference of the associations we observed. Third, it is possible that we only scored part of the decision-making process if decisions were distributed over more than one consultation. Our approach to analysis is comparable to that in earlier studies, ${ }^{7}$ so this does not affect comparison of our results to those found in the literature. Fourth, our study was performed in a single, large hospital in the Netherlands, which may have limited the generalisability of our results to other settings and countries. Finally, like in earlier studies using the OPTION ${ }^{5}$ instrument, our study focused on clinician behaviour and not on not on patients' experiences. Given the scant literature on the topic, ${ }^{2028} 29$ more studies are needed to assess how patients experience the decision-making process in medical consultations

\section{CONCLUSION AND PRACTICAL IMPLICATIONS}

Our study shows that medical consultants are unable to assess their own decision making-behaviour in medical encounters. This undermines the validity of SDM research using self-reported measures. Even more importantly, the consultants' unconscious incompetence in SDM hampers transfer of this crucial communication skill to students and junior doctors. In addition, consultants' motivation to participate in effective SDM training programs ${ }^{30-32}$ is likely to increase when they are consciously aware of their incompetence in practising SDM. Our results therefore support the use of videorecorded patient consultations to help consultants regularly review, reflect on and increase their awareness of their own decision-making behaviours. This, in turn, may promote consultants' willingness to participate in SDM training programmes, which is necessary for further implementation of SDM in clinical practice.

Twitter Anne M Stiggelbout @AMStiggelbout and Paul L P Brand @paulbrandzwolle Acknowledgements We thank the consultants and the patients who participated in this study. We thank R Hartog for help with the data collection, Dr. R Brohet for help with data analysis and we thank T Bouwkamp-Timmer for editorial help.

Contributors EMD designed the study, collected data, analysed data. She is the principal author of the manuscript and responsible for the overall content as guarantor. AMS assisted in the design of the study, the interpretation of the data and the editing of the manuscript. PLPB designed the study, supervised data analysis and interpretation, and edited the manuscript. The corresponding author attests that all listed authors meet authorship criteria and that no others meeting the criteria have been omitted.

Funding This research was supported by a research grant from the Isala Hospital's Innovation and Research Fund (IN01602).

Disclaimer We confirm the independence of researchers from funders and that all authors, external and internal, had full access to all of the data (including statistical reports and tables) in the study and can take responsibility for the integrity of the data and the accuracy of the data analysis is also required.

Competing interests None declared.

Patient consent for publication Not applicable.

Ethics approval This study was approved by Isala Hospital's Ethical Review Board (file number 180706).

Provenance and peer review Not commissioned; externally peer reviewed.

Data availability statement Data are available on reasonable request. The data used and/or analysed during the current study are available from the corresponding author on reasonable request.

Supplemental material This content has been supplied by the author(s). It has not been vetted by BMJ Publishing Group Limited (BMJ) and may not have been peer-reviewed. Any opinions or recommendations discussed are solely those of the author(s) and are not endorsed by BMJ. BMJ disclaims all liability and responsibility arising from any reliance placed on the content. Where the content includes any translated material, BMJ does not warrant the accuracy and reliability of the translations (including but not limited to local regulations, clinical guidelines, terminology, drug names and drug dosages), and is not responsible for any error and/or omissions arising from translation and adaptation or otherwise.

Open access This is an open access article distributed in accordance with the Creative Commons Attribution Non Commercial (CC BY-NC 4.0) license, which permits others to distribute, remix, adapt, build upon this work non-commercially, and license their derivative works on different terms, provided the original work is properly cited, appropriate credit is given, any changes made indicated, and the use is non-commercial. See: http://creativecommons.org/licenses/by-nc/4.0/.

\section{ORCID iDs}

Ellen M Driever http://orcid.org/0000-0001-5644-4514

Anne M Stiggelbout http://orcid.org/0000-0002-6293-4509

Paul L P Brand http://orcid.org/0000-0002-1743-4193

\section{REFERENCES}

1 van der Weijden T, Post H, Brand PLP, et al. Shared decision making, a buzz-word in the Netherlands, the PACE quickens towards nationwide implementation.... Z Evid Fortbild Qual Gesundhwes 2017;123-124:69-74.

2 Stiggelbout AM, Pieterse AH, De Haes JCJM. Shared decision making: concepts, evidence, and practice. Patient Educ Couns 2015;98:1172-9.

3 Blumenthal-Barby J, Opel DJ, Dickert NW, et al. Potential unintended consequences of recent shared decision making policy initiatives. Health Aff 2019;38:1876-81.

4 Härter M, Moumjid N, Cornuz J, et al. Shared decision making in 2017: international accomplishments in policy, research and implementation. Z Evid Fortbild Qual Gesundhwes 2017;123124:1-5.

5 Carmona C, Crutwell J, Burnham M, et al. Shared decision-making: summary of NICE guidance. BMJ 2021;373:n1430. 
6 Spatz ES, Krumholz HM, Moulton BW. Prime time for shared decision making. JAMA 2017;317:1309-10.

7 Couët N, Desroches S, Robitaille H, et al. Assessments of the extent to which health-care providers involve patients in decision making: a systematic review of studies using the option instrument. Health Expect 2015;18:542-61.

8 Agbadjé TT, Elidor H, Perin MS, et al. Towards a taxonomy of behavior change techniques for promoting shared decision making. Implement Sci 2020;15:67.

9 Meijers MC, Noordman J, Spreeuwenberg P, et al. Shared decisionmaking in general practice: an observational study comparing 2007 with 2015. Fam Pract 2019;36:529-64.

10 Joseph-Williams N, Lloyd A, Edwards A, et al. Implementing shared decision making in the NHS: lessons from the magic programme. BMJ 2017;357:j1744.

11 Driever EM, Stiggelbout AM, Brand PLP. Shared decision making: physicians' preferred role, usual role and their perception of its key components. Patient Educ Couns 2020;103:77-82.

12 Pollard S, Bansback N, Bryan S. Physician attitudes toward shared decision making: a systematic review. Patient Educ Couns 2015;98:1046-57.

13 Ericsson KA. Deliberate practice and acquisition of expert performance: a general overview. Acad Emerg Med 2008;15:988-94.

14 De Leeuw JME. Introduction to Multilevel Analysis. In: De Leeuw JME, ed. Handbook of multilevel analysis. New York, USA: Springer Science + Business Media, 2008.

15 Elwyn G, Hutchings $\mathrm{H}$, Edwards A, et al. The option scale: measuring the extent that clinicians involve patients in decision-making tasks. Health Expect 2005;8:34-42.

16 Stubenrouch FE, Pieterse AH, Falkenberg R, et al. OPTION(5) versus OPTION(12) instruments to appreciate the extent to which healthcare providers involve patients in decision-making. Patient Educ Couns 2016;99:1062-8.

17 Glyn Elwyn SWG, Barr P. Observer OPTION-5 manual. In: Measuring shared decision making by assessing recordings or transcripts of encounters from clinical settings. The DartMouth Institute for Health Policy and Clinical Practice, 2018.

18 Dijkstra IS, Pols J, Remmelts P, et al. What are we preparing them for? development of an inventory of tasks for medical, surgical and supportive specialties. Med Teach 2013;35:e1068-77.

19 Maslow AH. Motivation and personality. 3 edn. Harper and Row, 1987.
20 Jackson JL, Storch D, Jackson W, et al. Direct-Observation cohort study of shared decision making in a primary care clinic. Med Decis Making 2020;40:756-65.

21 Légaré $F$, Thompson-Leduc $P$. Twelve myths about shared decision making. Patient Educ Couns 2014;96:281-6.

22 Pieterse AH, Stiggelbout AM, Montori VM. Shared decision making and the importance of time. JAMA 2019;322:25-6.

23 Søndergaard SR, Madsen PH, Hilberg O, et al. The impact of shared decision making on time consumption and clinical decisions. A prospective cohort study. Patient Educ Couns 2021;104:1560-1567.

24 Dobler CC, Sanchez M, Gionfriddo MR, et al. Impact of decision AIDS used during clinical encounters on clinician outcomes and consultation length: a systematic review. BMJ Qual Saf 2019;28:499-510.

25 Williams D, Edwards A, Wood F, et al. Ability of observer and self-report measures to capture shared decision-making in clinical practice in the UK: a mixed-methods study. BMJ Open 2019;9:e029485

26 Arborelius E, Timpka T. In what way may videotapes be used to get significant information about the patient-physician relationship? Med Teach 1990;12:197-208.

27 Pringle M, Stewart-Evans C. Does awareness of being video recorded affect doctors' consultation behaviour? Br J Gen Pract 1990;40:455-8.

28 Chewning B, Bylund CL, Shah B, et al. Patient preferences for shared decisions: a systematic review. Patient Educ Couns 2012;86:9-18.

29 Tamirisa NP, Goodwin JS, Kandalam A, et al. Patient and physician views of shared decision making in cancer. Health Expect 2017;20:1248-53.

30 Henselmans I, Brugel SD, de Haes HCJM, et al. Promoting shared decision making in advanced cancer: development and piloting of a patient communication aid. Patient Educ Couns 2019;102:916-23.

31 Geiger F, Liethmann K, Reitz D, et al. Efficacy of the doktormitSDM training module in supporting shared decision making - Results from a multicenter double-blind randomized controlled trial. Patient Educ Couns 2017;100:2331-8.

32 van Veenendaal $\mathrm{H}$, Voogdt-Pruis $\mathrm{H}$, Ubbink DT, et al. Effect of a multilevel implementation programme on shared decision-making in breast cancer care. BJS Open 2021;5. doi:10.1093/bjsopen/zraa002. [Epub ahead of print: 05 Mar 2021] 